\title{
Assessing an Educational Program to Improve Documentation and Reduce Pain in Hospitalized Patients
}

\author{
Nina Karlsen ${ }^{*}$, Ragnhild Haaland Kornmo ${ }^{2}$, Alfhild Dihle ${ }^{1}$ \\ ${ }^{1}$ Institute of Nursing and Health, Diakonhjemmet University College, Oslo, Norway \\ ${ }^{2}$ Department of Anaesthesia and Intensive Care, Diakonhjemmet Hospital, Oslo, Norway \\ Email: ${ }^{*}$ karlsen@diakonhjemmet.no
}

Received 22 March 2015; accepted 19 April 2015; published 22 April 2015

Copyright (C) 2015 by authors and Scientific Research Publishing Inc.

This work is licensed under the Creative Commons Attribution International License (CC BY). http://creativecommons.org/licenses/by/4.0/

c) (i) Open Access

\section{Abstract}

Few experimental studies have evaluated the efficacy of continuing educational programs aimed at the improvement of nurses' pain-management skills. This study assessed whether a standardized educational program aimed at nurses could increase the use of the Numeric Rating Scale-11 in both documenting and reducing postoperative pain-intensity levels in hospitalized surgical patients. The study had a quasi-experimental pre- and post-intervention design. Data were collected from records of surgical patients prior to and after the standardized educational program was completed. There were no significant differences between pre- and post-intervention groups in terms of either pain-documentation frequency or pain-intensity level. The study showed no increase in the frequency of postoperative pain documentation and no reduction of surgical patients' postoperative pain-intensity level. This finding indicates that the standardized educational program on postoperative pain management was insufficient to bring about changes in clinical practice.

\section{Keywords}

Educational Program, Documentation, Numeric Rating Scale, Pain Assessment, Postoperative Pain

\section{Introduction}

Important goals of managing postoperative pain (POP) are to minimize pain and discomfort, facilitate the recovery process, and avoid complications [1]. Strong unrelieved POP increases the risk for developing chronic

\footnotetext{
${ }^{*}$ Corresponding author.
}

How to cite this paper: Karlsen, N., Kornmo, R.H. and Dihle, A. (2015) Assessing an Educational Program to Improve Documentation and Reduce Pain in Hospitalized Patients. Open Journal of Nursing, 5, 361-369. 
pain after surgery [2]-[4]. In spite of increased knowledge about pain, effective POP management is still a major challenge, and multiple studies have identified areas of poor clinical practice [4]-[11]. Nurses and physicians often underestimate pain [12] [13], and inadequate communication about pain between nurses and patients remains a problem in pain relief [9]. Karlsten et al. [14] argued that POP management success requires active postoperative pain assessment, improved staff training, regular staff meetings, and audits with feedback to the staff involved. The Norwegian Medical Association [15] recommends using a pain-rating scale-the Numeric Rating Scale-11 (NRS-11), in which 0 represents no pain and 10 represents the worst pain imaginable-to assess and treat POP in accordance with the International Association for the Study of Pain (IASP) [1]. The NRS-11 is a reliable and valid scale for assessing and evaluating POP management [16]. Because nurses play an important role in assessing and treating POP, they need to understand the proper use of pain scales [16] [17].

Several studies [18]-[20] have identified poor POP documentation in nursing records. In an investigation of the consistency between care given to patients postoperatively and what information is documented, De Marinis et al. [18] found that nursing records were inadequate for quality care evaluation because they did not include a comprehensive account of the care activities of the nurses.

Gunnarsdóttir et al. [21] conducted a systematic review of 11 experimental studies that evaluated the efficacy of educational programs aimed at improving the pain-management skills of health care professionals. Due to variations in methodology, patient population, setting, and intervention targets, only 4 of the 11 studies were relevant for the present study [22]-[25]. Francke et al. [22] [23] tested a comprehensive training program (eight three-hour sessions) aimed at surgical nurses in five Dutch hospitals. After the program's completion, no increase in the use of pain-rating scales was found [22]. However, the study indicated a positive effect on patients' pain intensity [23]. Ravaud et al. [24] found significant improvements in POP documentation and significant reductions in pain-intensity scores after 48-hour stays in surgical intervention units compared to stays of the same length in surgical control units. The intervention aimed at nurses included a one-hour educational program about pain and the use of a visual-analogue scale to assess pain. Michaels et al. [25] found no significant effect on POP documentation after an educational intervention in eight units compared to eight control units in which no intervention was conducted. This educational program comprised 20 - 30 minute lectures for staff followed by a video presentation.

Several comprehensive quality-improvement studies conducted between 2000 and 2005 have displayed positive results [14] [26] [27]. A pain-monitoring program for nurses proved to be effective in improving nurses' assessment of pain and documentation of pain in nursing records [26]. Warrén Stomberg et al. [27] studied the impact of database documentation of POP management of an anesthesia organized, nurse-based, anesthesiologist-supervised acute pain service on surgical wards over a two-year period. They found that about $60 \%$ of the data charts were properly completed and documented in the database and remained the same over the two year period [27]. Karlsten et al. [14] found that a three-year quality-improvement study using annual audits and education improved the use of the NRS-11 in surgical wards. Crawford et al. [28] reported that significantly fewer patients experienced mild and moderate pain subsequent to an intervention composed of postoperative analgesic protocols and supported by education of staff and patients. However, the percentage of patients who experienced severe pain remained the same after the intervention [28].

To our knowledge, only three studies with less comprehensive and expensive interventions have been conducted [24] [25] [28]. Because previous studies have shown different results regarding POP documentation and patients' pain-intensity level, more knowledge is needed regarding educational interventions that may help to increase nurses' use of the NRS-11 in POP management and to reduce patients' pain-intensity level. This paper focuses on educational programs designed to enhance nurses' use of assessment tools and documentation in POP management.

This study assessed whether a standardized educational program aimed at nurses could increase the use of the NRS-11 in documenting and reducing POP intensity level in hospitalized surgical patients.

\section{Methods}

\subsection{Design, Sample, and Setting}

The study had a quasi-experimental pre- and post-intervention design [29] and was a joint study between a university college and a hospital involving nursing students. The study was performed in four surgical units and the Post Anesthesia Care Unit (PACU) at a hospital in Norway. 
The inclusion criteria were records of hospitalized surgical patients aged 18 years and above who had undergone abdominal or orthopedic surgery with pain documented using theNRS-11 three times or more, from the day of surgery to the fifth postoperative day or discharge. Exclusion criteria were records of surgical patients with pain documented using theNRS-11fewerthan three times, from the day of surgery to the fifth postoperative day or discharge. Data were collected between September and December 2009 prior to the educational intervention and from May to October 2010 after the intervention.

\subsection{Instruments and Data Collection}

A registration instrument was developed based on the hospital's pain paper schema, which included the following variables: NRS-11 pain-intensity ratings on arrival at the PACU and on discharge from the PACU, NRS-11 pain-intensity ratings, on arrival to the surgical unit, NRS-11pain-intensityratings at rest and in movement in the surgical ward, whether or not analgesics were given when the pain-intensity level was above 3 on the NRS-11, and variables for nausea and other pains. The pain paper schema follows patients through the entire surgical trajectory, from arrival at the PACU to discharge from the hospital, and is part of the surgical patient's record. Additional demographic and clinical information was obtained on age, sex, preoperative risk in accordance with the American Society of Anesthesiologists (ASA), which is a 5-point scale, type of surgery, and type of anesthesia (main or supplementary anesthesia).

Data were collected from the hospital's pain paper schema in the patient's record and transferred into the registration instrument developed for this study.

Data were collected from the day of surgery until the fifth postoperative day or discharge. The data collection was performed by one nurse, and every 20th transferred registration was controlled. The educational program was pilot tested with eight nurses, who found it easy to understand. No corrections were made.

\subsection{The Educational Program}

The educational program included a 20-minute standardized PowerPoint presentation with 24 slides based on guidelines from the IASP [1] and a 15-minute discussion.

The PowerPoint presentation included the following:

1) Background: included a definition of pain [1], negative psychological and physiological effects of POP, barriers to and predictors of POP, and why it is important to use the NRS-11 when assessing POP;

2) Description of the NRS-11: the reliability and validity of the scale;

3) Proper use of the NRS-11: the importance of communicating pain, the aim of NRS $\leq 3$ in the postoperative phase, and how to ensure that the patient understands the scale and the method of documentation.

The discussion following the PowerPoint presentation was primarily concerned with the practical application of the NRS-11, how to inquire about pain, why to trust patients' self-reporting on pain, and the importance of documenting pain.

\subsection{Procedures for Nursing-Student Involvement and Educational-Program Implementation}

The educational program was carried out by 17 nursing students in either the second and third year of their bachelor's program as part of mandatory pedagogical training in clinical practice. The authors introduced the students to the educational program and provided them with a manuscript to support the Power Point presentation. During the presentation and the following discussion, the students were always accompanied by one of the authors. The standardized educational program was offered at various times during the day and evening shifts in order to facilitate participation.

All nurses in the four surgical units and the PACU were encouraged by the management to attend the educational program. However, participation was voluntary. On average, $80 \%$ of the nurses from the surgical units and $90 \%$ of those from the PACU attended the lectures, and a total of 123 nurses participated in 18 lectures with 2 - 15 nurses per lecture.

\subsection{Ethics}

In accordance with the Norwegian Regional Ethical Committee, it was unnecessary to obtain informed consent 
from the patients, nurses, and students. The nurses who participated in the educational program were informed about the project by their managers. The study was approved by the Norwegian Social Science Data Services and the hospital's Ethics Committee.

\subsection{Data Analysis}

Data were analyzed using SPSS version 17.0 for Windows (SPSS, Inc., Chicago, IL). Descriptive statistics were used to assess demographic and clinical characteristics, as well as pain-intensity scores. Owing to low data frequencies of the variables for other pains, nausea, vomiting, and whether or not analgesics were administered, these variables were omitted from the statistical analysis. Analyses on surgical-unit levels were not possible owing to the low frequency of data; hence, the four surgical units were collapsed into one unit. Results were recorded as mean, standard deviation (SD), median, range, and number (percentage). Differences between preand post intervention patient groups were analyzed using Student's independent-samples $t$-test and a chi-square test. Student's independent-samples $t$-test and/or the Mann-Whitney $U$ test were used to compare the mean scores of pain before and after the educational program. A $p$-value less than 0.05 indicated that the variable estimated was statistically significant.

\section{Results}

\subsection{Sample Characteristics}

The sample included 355 (40.8\%) of a total of 870 records from patients who had undergone abdominal or orthopedic surgery in the preintervention period and 363 (42.6\%) of a total of 852 records in the post intervention period. For conformity with the inclusion criteria, every record included in the sample had a pain paper schema in which POP was documented at least three times.

Approximately two-thirds of the patients were female, their mean age was in the low $60 \mathrm{~s}$, and both groups had a median ASA score of 2 (range 1 - 4). Table 1 summarizes the distribution of demographic and clinical characteristics. No differences were found in the demographic and clinical characteristics between the two groups.

Table 1. Demographic and clinical characteristics of the pre- and post-intervention groups.

\begin{tabular}{|c|c|c|c|c|}
\hline & \multicolumn{2}{|c|}{ Pre-intervention } & \multicolumn{2}{|c|}{ Post-intervention } \\
\hline & $\mathrm{N}^{\#}$ & (\%) & $\mathrm{N}^{\#}$ & (\%) \\
\hline Age (years mean $\pm \mathrm{SD}^{*}$ ) & 63 (mean) & $16\left( \pm \mathrm{SD}^{*}\right)$ & 62 (mean) & $16\left( \pm \mathrm{SD}^{*}\right)$ \\
\hline ASA (mean \pm SD*) & 2.2 (mean) & $0.6\left( \pm \mathrm{SD}^{*}\right)$ & 2.1 (mean) & $0.7\left( \pm \mathrm{SD}^{*}\right)$ \\
\hline \multicolumn{5}{|l|}{ Gender } \\
\hline Female & 232 & $(66)$ & 227 & (63) \\
\hline Male & 117 & (34) & 132 & (37) \\
\hline \multicolumn{5}{|l|}{ Surgery } \\
\hline Orthopedics & 295 & $(84)$ & 266 & (73) \\
\hline Abdominal & 56 & $(16)$ & 97 & $(27)$ \\
\hline \multicolumn{5}{|l|}{ Main anesthesia } \\
\hline General anesthesia & 175 & $(50)$ & 206 & (57) \\
\hline Blocks(spinal, epidural, regional) & 178 & $(50)$ & 155 & (43) \\
\hline \multicolumn{5}{|l|}{ Supplementary anesthetics } \\
\hline Epidural and regional nerve blocks & 84 & $(24)$ & 82 & (23) \\
\hline Local infiltration analgesia & 75 & $(47)$ & 77 & $(48)$ \\
\hline \multicolumn{5}{|l|}{ Local infiltration } \\
\hline Yes & 171 & (50) & 191 & (53) \\
\hline No & 170 & (50) & 167 & (47) \\
\hline
\end{tabular}

"SD: Standard deviation; " Sample size may vary due to missing data. 


\subsection{Frequency of Documentation and Level of Postoperative Pain Intensity}

On arrival at the PACU the median POP intensity level was 0.0 (Range 10) in the pre-test vs. 0.0 (Range 10) in the post-test, on discharge from the PACU median was 2.0 (Range 6) vs. 2.0 (Range 5), and on arrival at the surgical unit it was 2.5 (Range 8) vs. 2.8 (Range 7). Figure 1 shows the variation of the patients' pain-intensity scores. The frequency of POP documentation on arrival at the PACU was relatively high in both the pre- and post-test, whereas it was low at discharge in both periods. On arrival at the surgical unit it was even lower, as shown in Figure 1. There were no significant differences between pre- and post intervention groups in the frequency of POP documentation or level of pain intensity upon arrival at or departure from the PACU or on arrival at the surgical units.

As shown in Figure 2, the frequency of POP documentation at rest was higher during the evening shift in the pre-and post-test than during the day shift. The frequency was lowest during the night shift. The median POP intensity level at rest was 2.5 (Range 10) in the pre-test and 1.0 (Range 10) in the post-test during the day shift on the day of surgery (POD 0). During the evening shift the median was 3.0 (Range 10) vs. 2.5 (Range 10), and during the night shift it was3.0 (Range 10) vs. 3.0 (Range 8). The variation of the patients' pain-intensity scores is shown in Figure 2. No significant differences were found between the groups with respect to documentation and POP intensity level at rest on the day of surgery.

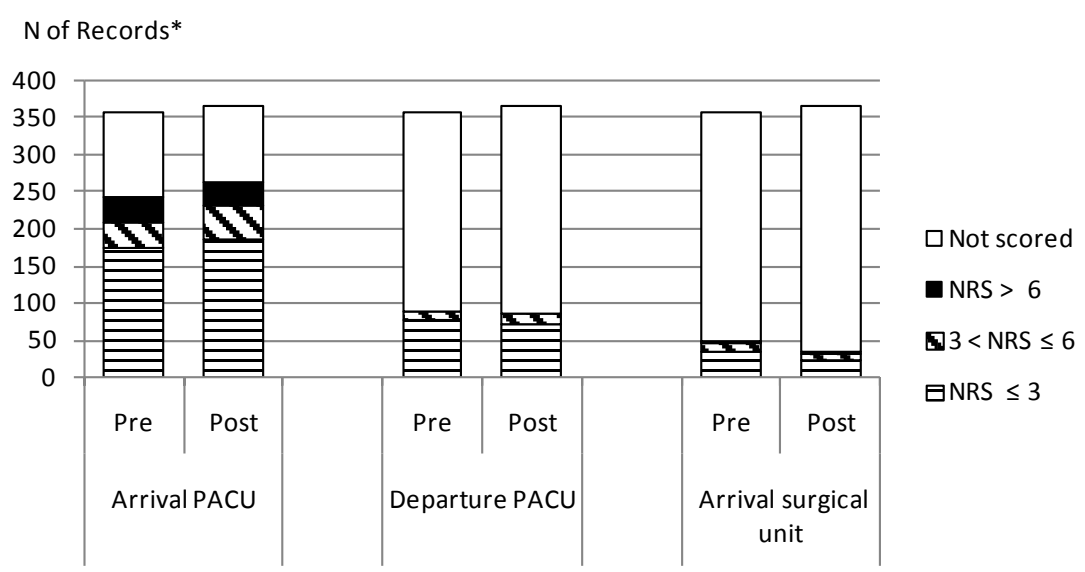

Figure 1. Frequency of POP documentation and level of pain intensity using the NRS-11 scale on arrival and departure from the PACU and on arrival to surgical unit for the pre- and post-intervention groups. * Number of records of surgical patients with POP documented three times or more.

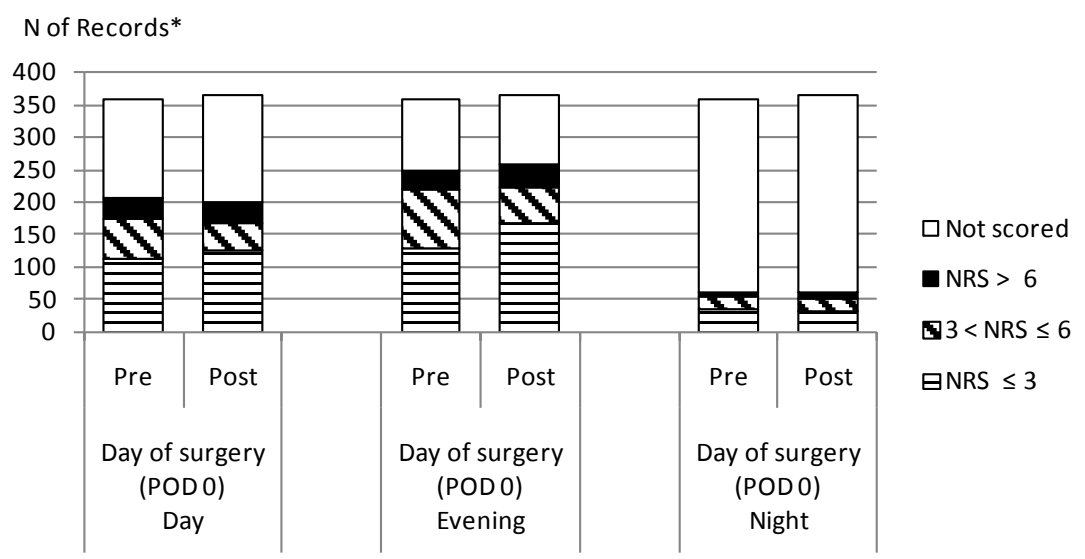

Figure 2. Frequency of POP documentation and level of pain intensity using the NRS-11 at rest during day, evening, and nightshifts on the day of surgery (POD0) for the pre- and post-intervention groups. *Number of records of surgical patients with POP documented three times or more. 
As Figure 3 shows, POP documentation occurred with low frequency in the surgical unit, and data on POP intensity level were consequently scarce on the first day of surgery (POD 1).

The frequency of POP documentation using the NRS-11from the second to the fifth postoperative day was so low that these data were omitted from the analyses.

\section{Discussion}

This study assessed whether a standardized educational program could increase the documentation of pain and reduce the POP intensity level of hospitalized surgical patients. The results showed no significant difference in the frequency of POP documentation, which agrees with the findings of Michaels et al. [25]. The duration of the educational program in that study was similar to ours, although the content differed to some extent. In the Michaels et al. study, in addition to offering a video presentation after the educational session, four clinical nurse specialists conducted the education program [25], whereas in the present study nursing students conducted the educational program with support from the authors. In Michaels et al.'s study, the discussion focused on the difference between acute and chronic pain, whereas the focus of the discussion in our study was on acute pain. Both programs offered discussions on common myths and barriers associated with pain management.

In contrast to our study, Ravaud et al. [24] found that an educational program for nurses led to significant improvements in POP documentation. The content of their educational program, which involved a 20 - 30 minute lecture, seemed quite similar to ours. In addition, their program was extended with a video presentation and individual feedback, and the main educators were an anesthetist who was an expert in pain management and a chief nurse. In our study, the main educators were students, and this may have influenced how important the nurses considered the message to be, which may have affected our results. It is interesting to note that Ravaud et al.'s assessment was performed48 hours after the intervention, whereas in our study it was performed after a minimum of three months. The studies of de Rond et al. [26] and Warrén Stomberg et al. [27] found positive effects on POP documentation. However, the more comprehensive interventions conducted in those studies may explain their positive results. Improving nurses' knowledge and changing their attitudes toward pain management seems to take a significant amount of time and effort.

The discussion that followed the educational program in our study often concerned whether nurses could trust patients' self-report of pain. In the educational program, we gave an example of how a patient can self-report a pain level of 7 on the NRS-11 and still retain the ability to read a newspaper. Some nurses questioned this example and stated they would not trust such a patient's subjective report of pain. However, not trusting patients' self-report of pain is seen as a barrier to effective POP pain relief [1]. As a lived, subjective experience, pain is difficult to measure, and it differs from other vital signs (pulse and blood pressure) that are objective and easily measured.

Previous studies have shown that nurses in general maintain low levels of documentation of their nursing

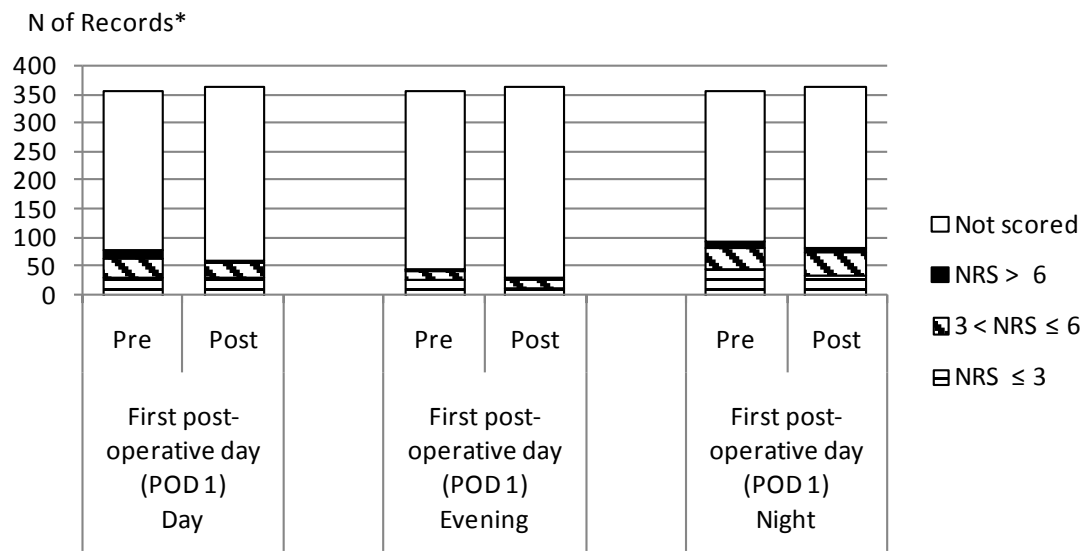

Figure 3. Frequency of POP documentation and level of pain intensity using the NRS-11 scale at rest during day, evening, and nightshifts on the first postoperative day (POD 1) for the pre- and post-intervention groups. * Number of records of surgical patients with POP documented three times or more. 
activities [18] [19] [30]. De Marinis et al. [18] found that nurses prioritize patient care and that they do more than they record. This finding may apply to our study. In the hospital where our study took place, pain should be documented primarily in the pain paper schema, but it can also be documented in the patient's records. This is potentially confusing, because it may be perceived as a double system of documentation. The pain paper schema used by the hospital in this study is rather comprehensive, and it maybe too complex to be used for regular documentation by busy nurses. In Norway, however, nurses have a general obligation to document relevant observations and interventions [31]. POP management is one of many nursing activities that should be documented, but the failure to do so has no serious consequences in Norwegian hospitals today.

In this study, no significant reductions in the patients' POP intensity levels were found three months after the education program. This result contrasts with the studies of Ravaud et al. [24] and Crawford et al. [28], which found reduced POP intensity scores after an educational intervention. However, in Ravaud et al. [24], the assessment was performed 48 hours after the intervention, compared to three months in our study. To maintain the effect of an intervention over time, it seems to be essential to establish routines that use continuous feedback and auditing, as recommended by Warrén Stomberg et al. [27] and Karlsten et al. [14]. Crawford et al. [28] used a medical protocol in addition to the educational intervention, which may explain the differences between the results of that study and those of ours.

The results of our study showed that the mean pain-intensity level conformed to the guidelines of the IASP [1] and the Norwegian Medical Association [15], which recommend that the patient's POP intensity level should be treated and preferably held at 3 or below $(\leq 3)$ on the NRS- 11 in the acute postoperative phase. The distribution of pain-intensity scores indicated that there was a group of patients that continued to have moderate (3.5 - 6.0) and severe (>6.5 - 10) pain, which is in line with other studies [28] [32] [33].

Our study had several limitations. The inclusion of only one hospital reduces the generalizability of the results. Moreover, the study design would have been stronger if a control group had been included, and the exclusion of records from surgical patients with fewer than three NRS-11 documentations may have influenced the results. Finally, we collected data only from the pain paper schema and not from the patients' records, which may represent a weakness of this study. We suggest three areas for future research, 1) nurses' beliefs and attitudes as this remain a major barrier for optimal POP management and calls for nurses to audit their own practice [14], 2) developing a health care culture that promotes optimal pain management which is strongly related to unit leadership, values held by the staff, nurse competency, and effective quality programs that include process and outcome indicators of pain management [14] [20], and 3) implementation of the NRS-11 in the electronic record, because it would enable systematic data monitoring. Despite the fact that pain was assessed and registered as a vital sign and documented by nurses on a regular basis using an electronic device, Carr et al. [34] found that POP was suboptimal managed. However, Carr et al. [34] found that assessment and documentation increased using an electronic device which is a prerequisite for handling POP management.

\section{Conclusion}

The standardized educational program conducted as a single session in this study resulted in no increase in the frequency of POP documentation using the pain-rating scale (NRS-11) and no decrease of the POP intensity level in hospitalized surgical patients assessed after three months.

\section{Acknowledgements}

The hospital and the nursing college gave time and financial support to this quality improvement study.

\section{Conflict of Interest Statement}

We do not have any conflict of interest with any issue discussed in this article

\section{References}

[1] International Association for the Study of Pain (IASP) (2011) Global Year against Acute Pain, October 2010-October 2011. Fact Sheets. http://www.iasp-pain.org/Advocacy/Content.aspx?ItemNumber=1097

[2] Kehlet, H., Jensen, T.S. and Woolf, C.J. (2006) Persistent Postsurgical Pain: Risk Factors and Prevention. The Lancet, 367, 1618-1625. http://dx.doi.org/10.1016/S0140-6736(06)68700-X 
[3] Katz, J. and Seltzer, Z. (2009) Transition from Acute to Chronic Postsurgical Pain: Risk Factors and Protective Factors. Expert Review of Neurotherapeutics, 9, 723-744. http://dx.doi.org/10.1586/ern.09.20

[4] Fredheim, O.M., Kvarstein, G., Undall, E., Stubhaug, A., Rustøen, T. and Borchgrevink, P. (2011) Postoperativ smerte hos pasienter innlagt i norske sykehus (Postoperative Pain in Patients Admitted to Norwegian Hospitals). Tidsskrift for Den Norskelegeforening, 131, 1763-1767. http://dx.doi.org/10.4045/tidsskr.10.1129

[5] Manias, E., Bucknall, T. and Botti, M. (2005) Nurses' Strategies for Managing Pain in the Postoperative Setting. Pain Management Nursing, 6, 18-29. http://dx.doi.org/10.1016/j.pmn.2004.12.004

[6] Dihle, A., Helseth, S., Kongsgaard, U.E., Paul, S.M. and Miaskowski, C. (2006) Using the American Pain Society’s Patient Outcome Questionnaire to Evaluate the Quality of Postoperative Pain Management in a Sample of Norwegian Patients. The Journal of Pain, 7, 272-280. http://dx.doi.org/10.1016/j.jpain.2005.11.005

[7] Fletcher, D., Fermanian, C., Mardaye, A. and Aegerter, P. (2008) A Patient-Based National Survey on Postoperative Pain Management in France Reveals Significant Achievements and Persistent Challenges. Pain, 137, 441-451. http://dx.doi.org/10.1016/j.pain.2008.02.026

[8] Sawyer, J., Haslam, L., Robinson, S., Daines, P. and Stilos, K. (2008) Pain Prevalence Study in a Large Canadian Teaching Hospital. Pain Management Nursing, 9, 104-112. http://dx.doi.org/10.1016/j.pmn.2008.02.001

[9] Dihle, A., Bjolseth, G. and Helseth, S. (2006) The Gap between Saying and Doing in Postoperative Pain Management. Journal of Clinical Nursing, 15, 469-479. http://dx.doi.org/10.1111/j.1365-2702.2006.01272.x

[10] Schoenwald, A. and Clark, C.R. (2006) Acute Pain in Surgical Patients. Contemporary Nurse, 22, 97-108. http://dx.doi.org/10.5172/conu.2006.22.1.97

[11] Bell, L. and Duffy, A. (2009) Pain Assessment and Management in Surgical Nursing: A Literature Review. British Journal of Nursing, 18, 153-156. http://dx.doi.org/10.12968/bjon.2009.18.3.39042

[12] Sloman, R., Wruble, A.W., Rosen, G. and Rom, M. (2006) Determination of Clinically Meaningful Levels of Pain Reduction in Patients Experiencing Acute Postoperative Pain. Pain Management Nursing, 7, 153-158. http://dx.doi.org/10.1016/j.pmn.2006.09.001

[13] Gunningberg, L. and Idvall, E. (2007) The Quality of Postoperative Pain Management from the Perspectives of Patients, Nurses and Patient Records. Journal of Nursing Management, 15, 756-766. http://dx.doi.org/10.1111/j.1365-2934.2006.00753.x

[14] Karlsten, R., Strom, K. and Gunningberg, L. (2005) Improving Assessment of Postoperative Pain in Surgical Wards by Education and Training. Quality and Safety in Health Care, 14, 332-335. http://dx.doi.org/10.1136/qshc.2004.010330

[15] Norwegian Medical Association (2009) Retningslinjer for smertelindring (Guidelines for Pain Relief). http://legeforeningen.no/pagefiles/42355/retningslinjer\%20smertebehandling\%20dnlf.pdf

[16] Williamson, A. and Hoggart, B. (2005) Pain: A Review of Three Commonly Used Pain Rating Scales. Journal of Clinical Nursing, 14, 798-804. http://dx.doi.org/10.1111/j.1365-2702.2005.01121.x

[17] Chanvej, L., Petpichetchian, W., Kovitwanawong, N., Chaibandit, C., Vorakul, C. and Khunthong, T. (2004) A Chart Audit of Postoperative Pain Assessment and Documentation: The First Step to Implement Pain Assessment as the Fifth Vital Sign in a University Hospital in Thailand. Journal of the Medical Association of Thailand, 87, 1447-1452.

[18] De Marinis, M.G., Piredda, M., Pascarella, M.C., Vincenzi, B., Spiga, F., Tartaglini, D., Alvaro, R. and Matarese, M. (2010) “If It Is Not Recorded, It Has Not Been Done!”? Consistency between Nursing Records and Observed Nursing Care in an Italian Hospital. Journal of Clinical Nursing, 19, 1544-1552. http://dx.doi.org/10.1111/j.1365-2702.2009.03012.x

[19] Samuels, J.G. and Kritter, D. (2011) Pain Management Documentation: Analyzing One Hospital's Computerized Clinical Records. CIN: Computers, Informatics, Nursing, 29, 512-518. http://dx.doi.org/10.1097/NCN.0b013e31821a1582

[20] Lewen, H., Gardulf, A. and Nilsson, J. (2010) Documented Assessments and Treatments of Patients Seeking Emergency Care Because of Pain. Scandinavian Journal of Caring Sciences, 24, 764-771. http://dx.doi.org/10.1111/j.1471-6712.2010.00774.x

[21] Gunnarsdottir, S. and Gretarsdottir, E.P. (2011) Systematic Review of Interventions Aimed at Nurses to Improve Pain Management. Vard I Norden: Nursing Science and Research in the Nordic Countries, 31, 16-21.

[22] Francke, A.L., Luiken, J.B., de Schepper, A.M., Abu-Saad, H.H. and Grypdonck, M. (1997) Effects of a Continuing Education Program on Nurses' Pain Assessment Practices. Journal of Pain and Symptom Management, 13, 90-97. http://dx.doi.org/10.1016/S0885-3924(96)00267-9

[23] Francke, A.L., Garssen, B., Luiken, J.B., de Schepper, A.M., Grypdonck, M. and Abu-Saad, H.H. (1997) Effects of a Nursing Pain Program on Patient Outcomes. Psycho-Oncology, 6, 302-310.

http://dx.doi.org/10.1002/(SICI)1099-1611(199712)6:4<302::AID-PON284>3.0.CO;2-D 
[24] Ravaud, P., Keita, H., Porcher, R., Durand-Stocco, C., Desmonts, J.M. and Mantz, J. (2004) Randomized Clinical Trial to Assess the Effect of an Educational Programme Designed to Improve Nurses’ Assessment and Recording of Postoperative Pain. British Journal of Surgery, 91, 692-698. http://dx.doi.org/10.1002/bjs.4506

[25] Michaels, T.K., Hubbartt, E., Carroll, S.A. and Hudson-Barr, D. (2007) Evaluating an Educational Approach to Improve Pain Assessment in Hospitalized Patients. Journal of Nursing Care Quality, 22, 260-265. http://dx.doi.org/10.1097/01.NCQ.0000277784.14310.66

[26] deRond, M.E., de Wit, R., van Dam, F.S.A.M. and Muller, M.J. (2000) A Pain Monitoring Program for Nurses: Effects on Communication, Assessment and Documentation of Patients' Pain. Journal of Pain and Symptom Management, 20, 424-439. http://dx.doi.org/10.1016/S0885-3924(00)00209-8

[27] Stomberg, M.W., Lorentzen, P., Joelsson, H., Lindquist, H. and Haljamäe, H. (2003) Postoperative Pain Management on Surgical Wards - Impact of Database Documentation of Anesthesia Organized Services. Pain Management Nursing, 4, 155-164. http://dx.doi.org/10.1016/S1524-9042(03)00032-8

[28] Crawford, F.I.J., Armstrong, D., Boardman, C. and Coulthard, P. (2011) Reducing Postoperative Pain by Changing the Process. British Journal of Oral and Maxillofacial Surgery, 49, 459-463. http://dx.doi.org/10.1016/j.bjoms.2010.07.012

[29] Polit, D.F. and Beck, C.T. (2012) Nursing Research: Principles and Methods. 9th Edition, Lippincott Williams \& Wilkins, Philadelphia.

[30] Kohle-Ersher, A., Chatterjee, P., Osmanbeyoglu, H.U., Hochheiser, H. and Bartos, C. (2012) Evaluating the Barriers to Point-of-Care Documentation for Nursing Staff. CIN: Computers, Informatics, Nursing, 30, 126-133. http://dx.doi.org/10.1097/NCN.0b013e3182343f14

[31] The Health Personnel Act. Act of 2 July 1999 No. 64 Relating to Health Personnel etc. (With Amendments Made Previous to 1 July 2002)

http://www.regjeringen.no/nb/dep/hod/dok/lover_regler/reglement/2002/act-of-2-july-1999-no-64-relating-to-hea.html ?id=107079

[32] Gramke, H.-F., de Rijke, J.M., van Kleef, M., Raps, F., Kessels, A.G.H., Peters, M.L., Sommer, M. and Marcus, M.A.E. (2007) The Prevalence of Postoperative Pain in a Cross-Sectional Group of Patients after Day-Case Surgery in a University Hospital. Clinical Journal of Pain, 23, 543-548. http://dx.doi.org/10.1097/AJP.0b013e318074c970

[33] Liu, S.S., Buvanendran, A., Rathmell, J.P., Sawhney, M., Bae, J.J., Moric, M., Perros, S., Pope, A.J., Poultsides, L., Valle, C.J.D., Shin, N.S., McCartney, C.J.L., Ma, Y., Mahendrakumar, S., Wood, M.J., Manion, S.C. and Sculco, T.P. (2012) Predictors for Moderate to Severe Acute Postoperative Pain after Total Hip and Knee Replacement. International Orthopaedics, 36, 2261-2267. http://dx.doi.org/10.1007/s00264-012-1623-5

[34] Carr, E.C.J., Meredith, P., Chumbley, G., Killen, R., Prytherch, D.R. and Smith, G.B. (2013) Pain: A Quality of Care Issue during Patients’ Admission to Hospital. Journal of Advanced Nursing, 70, 1391-1403.

http://dx.doi.org/10.1111/jan.12301 